\title{
TeCNOlogías PARA UNA SOCIEDAD ABIERTA POSTHUMANA ${ }^{1}$
}

\author{
Juan Bautista Bengoetxea ${ }^{2}$
}

Resumen: El texto se divide en dos partes. En la primera presento el desarrollo del cíborg como entidad cultural y tecnológica examinada desde el prisma de la teoría de la mente, donde se subraya la importancia de diversos elementos ficcionales y reales. En la segunda parte reflexiono acerca del futuro que la sociedad tecnológica y cíborg puede deparar al ser humano. En particular, mi objetivo es mostrar que los seres posthumanos constituyen una realidad ya establecida que exige una reflexión de índole moral y social que apunte al papel de los expertos en relación con las necesidades de los ciudadanos no-expertos. La conclusión final aboga por la constitución de normas y regulaciones que permitan encauzar los avances tecnológicos posthumanos en concordancia con éticas aplicadas a los humanos.

Palabras Clave: Cíborg. Posthumano. Expertos. Tecnología. Sociedad abierta.

\section{INTRODUCCIÓN}

El 'cíborg' (cyborg) es el organismo que se regula y controla a sí mismo mediante la integración de sistemas naturales y artificiales. La integración es una noción clave para entender esto y el hecho de que en un cíborg algunas capacidades que poseemos tanto humanos como máquinas se pueden retroalimentar. Esto es lo que nos aproxima a la primera imagen de ser 'posthumano'. Gran parte de la reflexión acerca de la relación entre seres humanos y tecnologías del conocimiento y de la información avanza a ciegas. Tendemos a vestir antropomórficamente al cíborg, a modo de androide, con tal de facilitar su identificación. Fueron Clynes y Kline quienes en 1960 nos

\footnotetext{
${ }^{1}$ Quisiera agradecer el apoyo económico recibido de las siguientes instituciones y proyectos de investigación: Fondos para el Desarrollo Regional Europeo (FEDER) de la Comisión Europea; Ministerio de Ciencia, Innovación y Universidades (Agencia Estatal de Investigación (AEI)) del Gobierno de Espańa; y Proyecto de Investigación 'Estándares de prueba y elecciones metodológicas en la fundamentación científica de las declaraciones de salud' (FFI2017-83543-P).

2 Profesor Titular de Lógica y Filosofía de la Ciencia en el Departamento de Filosofía de la Universitat de les Illes Balears (UIB), Palma - España. (D) https://orcid.org/0000-0003-1158-1122
}

E-mail: juanbautista.bengoechea@uib.cat

https://doi.org/10.1590/0101-3173.2021.v44n1.12.p177 
presentaron al primer cíborg real, si bien la forma que le dieron no favoreció una entrada exitosa en el mundo de los mortales. Se trataba de un ratón de laboratorio con una jeringuilla adosada; fue el primer cíborg pretendido, aunque falto de glamour.

Con el objetivo de reflexionar en torno al futuro de una sociedad abierta posthumana, divido el texto en dos partes. En la primera repaso la creación y el desarrollo del cíborg como entidad cultural y tecnológica relacionada simbióticamente con la mente humana, avance en el que subrayo la importancia de ciertos elementos tanto especulativos como científicos. En la segunda parte reflexiono acerca del futuro que la sociedad tecnológica y cíborg puede depararnos una vez que reconocemos la ya palpable realidad de los seres posthumanos. Mi propósito es reflexionar sobre la posibilidad y conveniencia de situarlos, junto a nosotros los humanos, en el seno de una sociedad abierta no-dicotómica en la que los expertos estén más próximos a las necesidades de los no-expertos. La conclusión busca ser un aporte prospectivo para una sociedad abierta. El método que sigo en el texto no es puramente analítico ni fenomenológico ni inductivo, sino propiamente ensayístico (entendido como intento); es decir, mi punto de partida es aquello que precisamente busco. Se plantea un objetivo al que quiero llegar, una conclusión básica de la que parto y que, a medida que el texto avanza, y debido a los meandros argumentativos y a las diversas implicaciones, se hace más compleja y se convierte en la cuestión final.

\section{1 ¿QUÉ es 'LO NATURAL’? TECNOLOGía Y CÍBORGS}

Tendemos a aceptar como naturales, a riesgo de ser circulares, las cosas y los seres que tienen cabida en el orden natural de las cosas. Sin embargo, interrogamos acerca de la naturalidad a muchas cosas que evidentemente parecen naturales. En The Social Construction of What? (1999), Ian Hacking planteó la pregunta acerca de la naturalidad del siguiente modo: ‘Es X natural o es algo construido socialmente?'. Su reflexión al respecto señala que “preguntarse si 'algo' ha sido construido socialmente o no [es decir, poner en tela de juicio su ser natural] exige establecer de antemano varias condiciones de adecuación”.

Que algo sea construido significa que es no-natural, que no pertenece a un género natural. Es una perogrullada saber que una manzana es natural, pero los casos más interesantes son más borrosos. Si decimos que una cosa 
$\mathrm{X}$ no es natural, con ello afirmamos que su existencia depende de nosotros, somos sus creadores. Una segunda condición o respuesta diría que la cosa $\mathrm{X}$ no es necesaria. Si la hemos construido, es contingente. Una tercera condición diría que, en su condición actual, $\mathrm{X}$ es perjudicial, de ahí que generemos la preocupación por su posible transformación. Por ejemplo, en muchas corrientes del feminismo se afirma que el género es algo construido, pues es un concepto construido por el ser humano (el hombre), porque es contingente y porque es perjudicial para la mujer en su forma actual.

Estas tres condiciones reflejan el posicionamiento del construccionismo social (HACKING, 1999, p. 26). Este se opone a las ideas más esencialistas según las cuales muchos de los objetos, ahora reconocidos como construidos, eran algo bien establecido, próximo a lo natural. Pues bien, también el cíborg es algo construido y, por lo tanto, no es natural. Se construye tecnológicamente. Pero, ‘es siempre algo construido el cíborg?' Cabe la respuesta negativa o, al menos, las dudas ante el 'sí rotundo. Si los humanos somos cíborgs de alguna manera, como señala Clark, ${ }^{3}$ entonces o bien el cíborg es natural en la medida en que nosotros los humanos también lo somos, o bien los seres humanos somos algo construido en la medida en que el cíborg también lo es. No hay respuesta clara al respecto, pero sabemos que pocas cosas son puras y que la fusión abunda en el mundo. Con el término 'puro' me refiero a eso que los seres humanos supuestamente poseemos como propiamente humano. La tradición del pensamiento cartesiano mantuvo y mantiene que precisamente el ámbito 'propiamente humano' es virgen, inexplorado por animales no humanos y por máquinas.

La pregunta por la supuesta esencia ha rondado la práctica y el pensamiento filosófico, científico y artístico desde al menos la Antigüedad y son cada vez más profundas, interesantes e importantes las respuestas parciales y los debates que suscita. La clave de la cuestión es esta: ¿queda algo en nuestro seno humano que nos haga exclusivos y diferenciados del resto? ¿Algo que nos identifica unívoca y naturalmente frente al resto de seres vivos y de las máquinas 'pensantes'?

Entre quienes niegan que los humanos tengamos algo propio y único están los defensores de nuestra 'naturaleza' cíborg. Andy Clark y el filósofo de la mente David Chalmers defienden que la mente humana no es lo que está

3 Andy Clark (2003) señala que los seres humanos avanzamos incorporando en nosotros cada vez más propiedades cíborg. Con ello enfatiza el carácter de la respuesta no cualitativa a la pregunta por la supuesta esencia de este tipo de organismos. 
solo dentro del cráneo. ${ }^{4}$ Consideran que la mente se puede extender hacia fuera, más allá del cráneo esquelético, y expandirse en formas variadas. Creen que existen andamiajes materiales exteriores al cráneo que a su vez ya son parte de nuestra mente. Clark es un claro exponente de la ciborgfilia. Los defensores del 'sí encuentran la cualidad propiamente humana, única, en el interior precisamente de la mente, o en ella como tal. No es algo físico, ni siquiera genético, lo que nos distingue. El término 'cíborg' proviene de la palabra griega 'cibernetes', que significa piloto o timonel en español. El cíborg es por ende el que o lo que se controla, dirige, conduce a sí mismo. Fue creado en el ámbito de la ingeniería y la medicina. Aunque de naturaleza extremadamente artificial al principio, siempre ha sido muy real, perceptible, existente. La ficción tardó poco en adaptar las prestaciones del cíborg a sus narraciones fantásticas. De este modo, gracias a la cibernética, a las nuevas tecnologías, al conocimiento científico y literario, a la reflexión filosófica acerca de la mente y a muchos análisis culturales, sociológicos y politológicos se ha ido dando forma a los ingredientes de todo un contexto cíborg hoy denominado 'ciborgología'. Por ende, la figura del cíborg ha pasado a ser parte del acervo común, se ha extendido de tal modo que las novelas gráficas, la literatura rápida, la escultura o las diversas formas narrativas de lo artificial la han hecho suya.

He mencionado anteriormente a quienes defienden que los seres humanos tenemos algo único distintivo. Hoy día no afirman que esto sea el lenguaje o el pensamiento a secas, sino que recurren a conceptos más elaborados. En particular, hablan de la conciencia y de la intencionalidad. Serían estas propiedades las que nos harían seres únicos. ¿O acaso podrían tener conciencia e intencionalidad las computadoras?

El asunto se originó explícitamente en 1980 cuando Searle diseñó un experimento imaginario que llamó 'la habitación china' (SEARLE, 2000, p. 188-190). Nos pedía Searle que imaginásemos a alguien en una habitación, aislado y solo, a quien dejáramos en el lugar una cesta repleta de trozos de papel en los cuales apareciesen escritos símbolos de apariencia china, a modo de ideogramas. La persona de la habitación no dominaba ningún dialecto del idioma chino, pero los experimentadores le proporcionaron un manual de reglas, en español, para que se desenvolviese con las palabras en chino. Las reglas le decían cómo manejar los símbolos chinos de una manera sintáctica, formal, sin semántica ninguna involucrada en ello. Pongamos por caso que una regla dijese que eligiese el símbolo del papel 1 (que podría

${ }^{4}$ Esta y otras ideas parecidas las publicaron inicialmente en el artículo 'The Extended Mind' de 1998. 
representar o estar en lugar de una silla) y que lo colocara a la izquierda del símbolo del papel 5 (que representa $a z u l$ ). De este modo, habría construido (junto con la cópula y un artículo determinado) la frase 'la silla es azul'. Con muchos más elementos (más trozos de papel con símbolos y nuevas reglas), la persona podía responder a preguntas de los experimentadores con tan solo recurrir al manual de reglas. Imaginemos ahora que se trata de una persona muy hábil que en poco tiempo aprende a manipular los símbolos con rapidez de forma que responda casi automáticamente a las preguntas. ¿Sabrá chino entonces? Según Searle, no; ni lo sabe ni lo podrá aprender nunca solo sintácticamente. La manipulación sintáctica de símbolos no es suficiente para captar el significado del lenguaje ni, por ello, conceptualizar adecuadamente la intencionalidad (BENNETT et al., 2007). ${ }^{5}$

¿Qué nos diferencia crucialmente del resto de los animales y de las computadoras? Muchos han señalado que las máquinas, las computadoras, son artificiales, que no contienen espíritu (esprit, mind, mente) o alma o psique. Pues la pregunta principal del experimento imaginario de Searle era la misma que la de Turing en 1950 o la de Torres y Quevedo en 1914 (p.10): ¿puede pensar una máquina? ¿Puede tener discernimiento? En Meditación de la técnica (1939), Ortega y Gasset ya adelantaba la importancia de este tipo de cuestiones aparentemente tan conceptuales. Consideraba que precisamente son estas las más pertinentes, incluso desde una perspectiva práctica. La técnica es parte del trasfondo cultural más rico y meditar sobre ella nos conduce al misterio más raro del ser del hombre. "En el hueco que la superación de su vida animal deja, vaca el hombre a una serie de quehaceres no biológicos, que no le son impuestos por la naturaleza, que él inventa a sí mismo". (ORTEGA Y GASSET, 1939, p. 43). Es la cultura, cultivo y fermentación, ese proceso humano que requiere unos ingredientes de calidad para poder obtener resultados apropiados. La imagen del cíborg y de los paisajes post-humanos se podría situar precisamente en una cultura particular, la tecnológica. A inicios de la década de 1980 nacieron las computadoras IBM en los Estados Unidos y en 1984 el Apple Macintosh. Comenzaba a fraguarse una cultura informática o computacional de masas. En 1983, la revista Time eligió un computador como personaje del año. Pocos habían pronosticado con tiempo este éxito popular del silicio, menos aún de lo que a partir de 1993 también se hizo popular extensivamente: Internet.

5 Para saber más acerca de la actitud intencional de Dennett y su defensa de una concepción de la complejidad como elemento básico de la emergencia de propiedades mentales, véase Dennett (1987, 1996). 
En 2019 somos muchos millones los que navegamos en un proceloso ciberespacio parecido al que William Gibson buscaba en su novela Neuromancer (1984), aunque el prefijo 'ciber' en absoluto relega aún al ostracismo aquello que no es virtual o no esté en línea. Es la cultura cíborg. Con esto quiero señalar que la réplica a quienes consideran que las máquinas solo podrán desenvolverse en un nivel sintáctico afirma que el organismo post-humano más interesante proyectado por la ingeniería y por la ficción es el cíborg, una entidad que contaría con los ingredientes de carbono necesarios para dar el salto a la semántica y a la pragmática.

\section{EMERGE EL CÍBORG}

A partir del trabajo de Donna Haraway (1991), Andy Clark (2003, 2005) ha articulado una serie de resultados en torno a la noción de mente. Su tesis básica es que la mente es algo extensible. La mente humana, entendida como el órgano físico del razonamiento, no se limita a estar encerrada en nuestro cuerpo o cráneo (CLARK, 2003, p. 4). Al igual que Haraway, considera que hay que romper esta frontera clásica. ${ }^{6}$ Nunca la mente ha estado realmente limitada de este modo, al menos desde que existe la palabra. Siempre ha estado abierta hacia el exterior y ha trabajado codo con codo con fuentes no biológicas con el fin de solventar problemas relacionados con la supervivencia y la reproducción.

¿Cuál es entonces el papel o rol del cerebro biológico? La materia gris es muy eficaz para ciertos fines: hace experta a la gente en el reconocimiento de patrones, en la percepción y en el control de actividades físicas. No obstante, no está tan bien diseńada para realizar acciones de planificación sofisticada ni para producir resultados complejos a largo plazo. Es una herramienta para los detalles, las cosas nimias; no, así, para comprender bien la lógica de las relaciones humanas (TURNER, 2018, p. 92-95). Somos lo interior al cráneo, pero también lo que hay fuera y vinculado 'de cierto modo' a él. Matizo el 'de cierto modo' porque esto apunta al vínculo automático o no-inferencial entre la tecnología o andamiaje in-corporados y el cerebro humano, al procesamiento de información. Las prótesis que 'nos tocan' no son básicamente externas,

${ }^{6}$ El cíborg de Haraway es un organismo cibernético y un híbrido de máquina y organismo que ella elabora en el seno de un enfoque feminista opuesto a cualquier tipo de esencialismo (o identificación de una identidad de género universal y necesaria) y para el cual "no hay nada acerca de ser hembra que una naturalmente a las mujeres" (HARAWAY, 1991, p. 155); así pues, el cíborg no requiere una identidad estable y esencialista, según Haraway. 
sino ingredientes integrales interiorizados en nuestro sistema de resolución de problemas. Esto es, son prótesis de inteligencia.

Pensadores como Clark, Chalmers y Dennett dan la bienvenida a estos procesos automáticos - o que pretenden serlo - que conforman parte de nuestra caja de herramientas computacional-mental. ${ }^{7}$ Consideran que nuestra capacidad principal consiste precisamente en solucionar problemas. Hay otros animales a los que se les han injertado chips de silicio, pero estos dispositivos en realidad no modifican su conformación mental-cerebral, ni siquiera sus planes de acción. Una cobaya con un chip no muestra una simbiosis cobayamáquina, pues no es simbiótica en absoluto. Los humanos, en cambio, tenemos la tendencia a generar, elaborar, adosar y a valernos de prótesis y de herramientas computacionales (CLARK, 2003, p. 6-8). La cuestión que surge inmediatamente, sin embargo, es esta: ¡soy yo quien utiliza mi mente o es ella, junto con la tecnología, la que me constituye?

Si miramos a nuestro alrededor, vemos a la gente hablar por los celulares por doquier y en todo momento. Nos relacionamos sin cables, conectados a través de ondas; mis dedos vuelan sobre el teclado del SmartPhone, escucho música en la Nube, piso dígitos aquí y allá. Los finlandeses llaman 'kanny' ('extensión de la mano') al celular, al igual que el martillo era la extensión del brazo en algunas reflexiones de Heidegger sobre la técnica (HEIDEGGER, 1953). El celular es algo que los humanos usamos, pero también parte del ser humano usuario. Y manos y cerebro avanzan juntos en nuestra evolución biológica.

El cíborg es resultado de la cultura humana en cuanto la ciencia y la tecnología también lo son. El término 'cíborg' apareció por primera vez en la revista Astronautics en 1960, en un artículo titulado "Cyborgs and Space», basado en una conferencia de Manfred Clynes y Nathan Kline en la Escuela de Medicina de las Fuerzas Aéreas (San Antonio, Texas, Estados Unidos), y cuyo tema eran los medicamentos, el espacio y la cibernética. Los autores investigaban la forma de mejorar la salud de los astronautas, o de atacar la enfermedad con mejores medicamentos. Para ello, y dado que crear escenarios artificiales parecidos, si bien ligeramente modificados, a los de la Tierra con el fin de que el humano se acondicionara mejor al espacio exterior era dificultoso, los experimentadores indagaron sobre cómo podrían modificar al ser humano con fines adaptativos. Trabajaron con ratones de laboratorio en el ámbito de la

7 David Pineda ofrece un excelente tratamiento del funcionalismo y del modelo sintácticocomputacional de la mente en su libro La mente humana (2012). 
entonces denominada 'cibernética's y del procesamiento electrónico de datos. Combinaban, por ende, el enfoque cibernético y el computacional como mejor modo de crear un híbrido hipotético entre humano y máquina.

El turno del humano-cíborg llegó con el trabajo de Kevin Warwick en la década de 1990 (WARWICK, 2003). Se injertó un chip de silicio en su brazo, bajo la piel, el cual enviaba señales de radio a una computadora central por medio de una antena y, como consecuencia de ello, la computadora realizaba varias tareas (para las cuales estaba conectado) cuando Warwick se le aproximaba: encender y apagar luces, abrir ventanas, etc. El objetivo, aunque con consecuencias bastante rudimentarias en esa época, era mostrar que se podían enviar y recibir señales por medio del injerto.

En 2002 le injertaron un chip más interesante. Se trataba de un rectángulo diminuto con cien agujas que instalaron bajo la piel de su muńeca. Cada aguja estaba conectada a fibras nerviosas y a varios cables que cruzaban su brazo, y salía por un punto fijo de la piel donde había un dispositivo de radio transmisor-receptor. Este posibilitaba que el nervio medio del brazo se conectara con una computadora, de modo que los impulsos nerviosos que provenían del cerebro y de la mano estuviesen cableados y transmitieran señales a la computadora. Y viceversa: la computadora podía enviar señales al injerto y a la mano con el fin de ordenar acciones al cerebro. Dado que los nervios del brazo envían una cantidad enorme de información al cerebro, esta afectaba no solo al uso mecánico del brazo, sino también al placer, al dolor y a la neurofisiología de las emociones. La simbiosis era, por lo tanto, una consecuencia 'estimulativamente' más rica de lo que se pensaba. La posible preocupación del avance en el desarrollo de los cíborgs, no obstante, no radica tanto en la conexión entre la carne y los cables, o entre el animal y la máquina, sino más bien en su naturaleza transformadora general. De hecho, una vez que hemos imaginado y obtenido este tipo de conexión, entramos de lleno en un nuevo mundo. La clave, insisto con Clark (2003, p. 22), no es tanto la profundidad de la experimentación con injertos tecnológicos como lo que nos pueda deparar la fuerza transformadora de la bioelectrónica y de las nanotecnologías.

\footnotetext{
8 En la actualidad apenas hay departamentos de investigación que reciban este nombre. Por lo general, se llaman 'ciencias de la computación', 'ciencias cognitivas' o 'Inteligencia Artificial', por poner algunos ejemplos.
} 


\section{EL POSTHUMANO AMENAZADOR}

La distopía Un mundo feliz, de Aldous Huxley (1932), ha hecho reflexionar sobre la tecnología y el ser humano a uno de los politólogos más procaces: Francis Fukuyama. En 2002 sostenía que el 'pronóstico' de Huxley casi fracasa. ${ }^{9}$ Sin embargo, reconocía que Huxley proyecta algo refinado, sutil, fresco y no fácilmente predecible (FUKUYAMA, 2002, p. 5). La construcción que este hace de la 'maldad' tecnológica se aproxima mucho a lo que se critica a las nuevas tecnologías de hoy en día. En esto coincido con la lectura de Fukuyama. Pero, ¿qué dice que falla en Un mundo feliz, si algo lo hace? Según Fukuyama, en su mundo feliz, el humano no sufre, no enferma, no se degenera y no tiene emociones apenas. El humano no es entonces natural, no es del todo humano. Fukuyama sucumbe a la ambigüedad en este punto al señalar que no quiere oír hablar de esencias (la dignidad humana tal vez consista en entender que nosotros mismos hemos de transformar nuestro destino) y defender acto seguido que los seres humanos sí poseemos algún género de naturaleza distintiva. ¿No es esto una esencia? Sigue al pie de la letra a Huxley (FUKUYAMA, 2002, p. 7) y dice que la amenaza más evidente de la biotecnología es su capacidad de modificar la naturaleza humana, pues con ello será capaz de incorporarnos a una era post-humana. Obviamente, acepta Fukuyama que la esencia humana es una realidad; es lo que define, junto con la religión, nuestros valores.

Decíamos anteriormente que el cíborg cuenta con su propia teoría general: la ciborgología. Es un campo multidisciplinar, confuso a veces, pero que abre las puertas a entender el cíborg no solo como metáfora sino también como realidad en curso. Relativiza el esencialismo, exige superar muchas dicotomías decimonónicas y permite definir identidades híbridas (LANDGRAF et al., 2019, Parte III). A partir de aquí ha surgido una nueva concepción filosófica, social, política y cultural conocida como posthumanismo, creada en 1998 por Nick Bostrom y otros. ${ }^{10}$ Busca ir más allá del humanismo moderno y considera que para ello hemos de incorporar la reflexión y el uso de las tecnologías más avanzadas aplicadas al ser humano, pues nos facilitan extender nuestras facultades corporales y mentales. Muchas disciplinas

\footnotetext{
9 El análisis político e ideológico de Fukuyama (2002) es bastante conservador en cuanto defiende radicalmente la hegemonía humana. Sobre la base de las concepciones posthumanas de Bruno Latour y Andrew Pickering, en Jensen (2005) encontramos una lectura más desafiante ante los análisis filosóficos y sociológicos tradicionales.

10 Para algunas consideraciones interesantes sobre el posthumanismo, véanse http://www. posthumanism.com/ y Ferrando (2019, p. 54-59).
} 
científicas apuntan a una convergencia de este tipo, por ejemplo la ingeniería genética, la ingeniería biomédica, la inteligencia artificial, las nanotecnologías y las ciencias cognitivas. Gracias a ellas, piensan los posthumanistas, podremos trascender al humano. En este sentido, el posthumanista es un transhumanista (FERRANDO, 2019, p. 29-38).

¿Hay que temer al posthumanismo? En un principio, el posthumanismo desea seguir los pasos del humanismo secular. En este sentido, es moderno. Cuando, sin embargo, procura adelantar a la Ilustración - que idealiza en exceso -, es de hecho postmoderno. Se trata de un postmodernismo tecnocientíficamente ilustrado al cual subyace un interés, y conocimiento, de muchas actividades científicas y tecnológicas actuales. ${ }^{11}$ Desde que naciera el primer bebé probeta (Louise Brown) hace algo más de cuarenta años, se ha pensado que gracias a la ciencia aplicada y a los métodos racionales mejoraremos la salud humana, ampliando así nuestras capacidades intelectuales y aumentando el control de nuestra conducta. Para hacerlo, se ha solido hablar de las 'tecnologías para la mejora del ser humano', ${ }^{12}$ tecnologías que reclaman responsabilidad al usuario que supuestamente es libre de integrarse con ellas. Más allá de los riesgos existentes debidos a sus posibles aplicaciones al cuerpo humano (GOMES ROTONDARO, 2018, p. 223-224), estas tecnologías tienen un enorme potencial de ser empleadas adecuadamente, según el posthumanismo. La exigencia básica para ello es que nos conviertan en posthumanos: más sanos, con mayor capacidad intelectual, y equipados con nuevas formas de controlar las emociones. ¿Significa esto que la meta posthumanista trae consigo progreso tecnológico y avance moral? (NAYAR, 2014, p. 161-166; BENGOETXEA, 2011). Se obtenga o no algún progreso tecnológico y cognitivo con ello, habremos de cuidar los derechos que los humanos aún tenemos, así como nuestra soberanía personal, algo que los bioconservadores descartan desde un inicio al negarse a este tipo de desarrollo tecnológico. Consideran que la tecnología nos des-humaniza y lo temen. ${ }^{13}$

Coincido en una cosa con Bostrom. Según este, los argumentos de los críticos con el posthumanismo no se percatan de un hilo conductor clave,

\footnotetext{
${ }^{11}$ Acerca del conocimiento en la red y el Google-saber, las reflexiones de Lynch (2016), sobre todo la Parte I ('Los Nuevos Viejos Problemas del Conocimiento'), resultan sagitales y provocadoras.

${ }^{12}$ Algunos posthumanistas se arriesgan más si cabe y se atreven a hablar de inmortalidad. Un ejemplo de ello es el libro Becoming Immortal: Combining Cloning and Stem-Cell Therapy de Stanley Shostake (New York: SUNY Press, 2002).

${ }^{13}$ Además de Fukuyama, un crítico notable del desarrollismo tecnológico es Leon Kass (2002). Véanse especialmente las páginas 48 y 49.
} 
a saber: no se ocupan de reflexionar sobre el diseño del futuro humano ni del papel y las consecuencias de las tecnologías en él. Deberían examinar la influencia real que pueden tener las tecnologías, y no meramente reposar sobre su propia ideología personal y proyectarla acríticamente. Se posicionan contra el avance tecnológico y son fundamentalistas en su tarea de valoración de los datos (SAVULESCU; BOSTROM, 2009, p. 44; BOSTROM, 2005, p. 204). Parece que temen realmente al prospecto posthumanista por dos motivos: uno, porque piensan que el ser humano se degenerará en el proceso y, dos, porque creen que el posthumano será una amenaza para el humano. En cuanto al primer motivo, Kass defiende que la naturaleza, la evolución, ha dado al humano un carácter especial, propio de cada especie. El escarabajo y el ser humano casi coincidimos genéticamente, pero estamos naturalizados de distinto modo. Hemos adoptado una forma distinta y tenemos un quehacer propio, diferente al del escarabajo, en la naturaleza. Si alguien se 'metamorfosea' en Gregorio Samsa, se deshumaniza. Por eso deberíamos salvaguardar los dones que naturaleza nos ha concedido; en caso contrario, señala Kass (2002, p.48), nos convertiremos en "almas sin amor".

El posthumanismo sospecha de los supuestos humanos con dones naturales propios. ¿Constituye ese don una clase natural? ¿Existe realmente el don natural? Los géneros naturales son de gran ayuda desde una perspectiva epistemológica, pero también resultan confusos si los observamos desde un prisma ontológico. Cualquier género o clase aparentemente natural puede estar contaminado, al igual que las clasificaciones científicas que podrían sustituirlos. La mayoría, por no decir todos, son géneros artificiales o, por lo menos, contingentes. El cáncer puede ser natural, pero no tiene por qué ser necesario y eterno. Los avances tecnológicos pueden ayudarnos a hacerlo algo del pasado. Las enfermedades, las hambrunas o cualquier tipo de sufrimiento 'natural' es en realidad contingente desde una perspectiva ontológica.

La supuesta naturaleza propia de cada especie, en la jerga de Kass, es fuente de muchas cosas y acciones inaceptables: actitudes violentas, tendencias sexuales inaceptables, racismo, tortura, etc. La actitud de Kass me sorprende, ante todo cuando persigue clasificar normativamente lo que es correcto y lo que no. Frente a ello y al tremendismo neoludita, los posthumanistas creen que podemos reformarnos adecuadamente, desde un punto de vista cognitivo y moral, según valores (post-)humanos, no solo naturales (DE ASÍS, 2019, 
p. 5). ${ }^{14}$ Tendremos que defender nuestra libertad morfológica y reproductiva de los supuestos controladores de 'la sanidad y la moralidad' del mundo. La historia nos ha mostrado lo peligroso que es dejar en manos de los gobiernos esa libertad. Rememorando a Platón (República), no olvidemos que en el siglo $\mathrm{XX}$ varios gobiernos desarrollaron abominables programas de eugenesia. ${ }^{15}$

Respecto al segundo motivo antes mencionado, se trata del miedo a la falta de entendimiento entre el ser humano y el ser posthumano. Por ejemplo, Annas, Andrews e Isasi (2002, p.162) tachan la clonación humana y toda alteración genética diseñada de 'crimen contra la humanidad', dado que, si ocurriera esto, sería posible ver el nacimiento de una 'especie' posthumana que nos amenazase realmente. Nadie niega que la bio-violencia y la ingeniería genética que emplean medios de destrucción masiva amenazan seriamente la civilización - aunque de la mano de los humanos -; sin embargo, convendría matizar que la retórica antitecnológica a menudo oculta una agenda que incita a retrasar o detener la investigación biotecnológica de índole terapéutica. En la regulación y a la hora de prohibir, hay que buscar equilibrios y tomar decisiones consensuadas, pues las cuestiones sociales y políticas vinculadas a la tecnología, las jerarquías y el poder establecido, aunque sea del todo legalmente, tienden a exagerar la división entre peritos (expertos) y legos (ciudadanía). En muchos países existen marcos legales bien articulados, pero siempre reflejan un perfil ideal y su naturaleza democrática y de sociedad abierta solo se comprueba en la práctica aplicativa real. ¿Quién no ha sufrido decisiones impuestas y que afectan a quienes no las deciden? ¿ $\mathrm{O}$ aplicaciones tecnológicas incomprensibles para la población a la que más afecta? En estos casos es la voz del experto la que expresa la última palabra. Pero desde la década de 1980 la voz del experto es también tema controvertido y fundamental en la filosofía y la sociología de la ciencia (SHRADER-FRECHETTE, 1984, 1995). Por lo tanto, desde una perspectiva posthumanista y cíborg, si para llegar a posicionamientos de equilibrio no podemos dejar de lado la aplicación de tecnologías, la responsabilidad se convierte en una noción clave, más allá de la prudencia (BENGOETXEA, 2015, p. 98-102).

No obstante todo ello, pensar que las transformaciones genéticas heredables y las nuevas tecnologías nos conducen al nacimiento de dos especies distintas es bastante dudoso. Considero más plausible afirmar que, a

\footnotetext{
${ }^{14}$ Un nuevo manifiesto interesante acerca del diseño ético de los post-humanos es el Ethical Design Manifesto, accesible en https://2017.ind.ie/about/manifesto/.

${ }^{15}$ Cabe recordar el provocador texto 'Normas para el parque humano' (2000) de Peter Sloterdijk y su examen de la eugenesia.
} 
lo sumo, llegaremos a un estado sin solución de continuidad entre humanos y posthumanos, básicamente porque parece una idea cuerda pensar que los humanos 'mejorados' - ante todo quienes sufren enfermedades - y los humanos 'comunes' pueden convivir sin más problemas de los que tengan solo los humanos entre sí. Da la impresión de que el posthumanismo provocará el descontrol, y no es así necesariamente.

\section{TECNOLOGÍA Y SOCIEDAD ABIERTA: UN FUTURO ILUSIONANTE}

El poder de las tecnologías ha sido evidente y notable durante el siglo $\mathrm{XX}$. Algunos pensadores reflexionaron al respecto desde un prisma poco benévolo. Heidegger criticó el paso desde la técnica hasta la tecnología, y la Escuela de Frankfurt, así como los movimientos sociales de la década de 1960, trataron de desacreditar la tecnificación política porque sostenían que la política de poder y dominación se parapetaba en las nuevas tecnologías (HABERMAS, 1968, p. 55).

En el contexto del pasado siglo, los pensadores aún exigían una modernidad abstracta, pues pensaban que 'su' modernidad serviría de molde para la organización social. Sin embargo, también aquí surgieron controversias, entre las cuales cabe destacar la de las guerras de la ciencia. Desde la época de entreguerras, se había extendido y aceptado casi unánimemente la creencia en las torres de marfil científicas-técnicas. En ellas y su elitismo epistémico los científicos podían hacer lo que consideraban oportuno, pues se aceptaba que gracias a ellos se obtendría la transformación, progreso y mejora - más justa y sabia - social, política y económica. Hoy, sin embargo, reconocemos que la relación entre ciencia, tecnología y política es más bien pendular, una imagen que ha dado lugar al debate, mencionado anteriormente, acerca de los expertos (KURZ-MILCKE; GIGERENZER, 2004). ¿Qué es el conocimiento experto? ¿Qué aporta este tipo de conocimiento a la sociedad y a la política? ¿Mejora los prospectos tecnológicos? Cada vez tenemos más respeto, y miedo, al poder y control tecnológico, o al menos es algo que se percibe con mayor visibilidad, y esto nos hace sospechar más de las aplicaciones tecnológicas hasta el punto de que, al menos desde la sociología de la tecnología, se habla ya de que la tecnología invade la política - el caso de las últimas elecciones federales norteamericanas y el uso de las redes es uno de los más flagrantes al respecto - Si es así, la política entonces sería algo técnico, artificial, diseñado, difícil de entender directamente y cognitivamente elevado. Ahora bien, 
también sospechamos de la relación inversa, a saber: que la propia tecnología se está politizando, si no lo estaba ya. Aquí los críticos señalan por ende que la tecnología y la técnica son política y que, en consecuencia, la imagen científica tradicional - neutralidad epistémica y desinterés - es tan solo una máscara.

Tras cada una de las dos sospechas mencionadas, la tecnología se está convirtiendo en el chivo expiatorio por excelencia. Pero este relato parece recurrente: antes el enemigo era la naturaleza - inundaciones, huracanes, virus, animales horribles - y buscábamos alejarnos de ella; ahora lo es la tecnología, pues destruye el entorno, contamina, dirige nuestras vidas, crea adicciones, etc. La política se debería alejar de ella, y con aquella la moral. Muchos creen que esta es la separación que tenemos que realizar para evitar riesgos posibles. ¿No es esto acaso un claro ejemplo de razonamiento y formación de creencias sobre la base de deseos (wishful thinking)?

Las representaciones aludidas de la tecnología se implementan socialmente. Las prácticas tecnológicas y culturales sirven a nuestra coordinación social. Nuestro comportamiento es público, se puede observar, se organiza en el espacio y el tiempo, no únicamente en nuestra mente. Y existen artefactos y técnicas para nuestra construcción social. Podemos seguir patrones y constituir hábitos para comportarnos individual y socialmente, siempre que también respetemos el sistema perceptivo. La coordinación es fundamental en sociedad, más si se trata de una democracia de origen social abierto. El espacio público y el consenso son claves en las democracias de este tipo, aunque también lo sea a veces la fuerza, supeditada esta - idealmente - al acuerdo o consenso al que se llega por vías políticas y sociales. El lenguaje, la comunicación, son parte consustancial de la democracia; sin aquellos, sin la comunicación real en ambos sentidos direccionales (hablante $\rightarrow$ oyente $\rightarrow$ hablante $\rightarrow \ldots$ ) no hay democracia real, sino un simulacro de ella en el que solo se acepta la necesaria sintaxis del voto. Un estado democrático debería sacar a relucir sus condicionamientos tecnológicos en la medida en que es un estado cíborg, un estado con una estructura tecnológica. Toda la información, incluso la más fundamental relacionada con las votaciones políticas y sus recuentos, es solo un conjunto de datos numéricos proveniente de evidencias pasadas por el tamiz técnico y de inferencias realizadas a partir de aquellas. Y confiamos en todo ello. Foucault examinó los procedimientos tecnológicos de vigilancia en diversas instituciones (cárcel, hospital, psiquiátrico) que requieren tecnologías. La sociedad-mundo actual las necesita también. Al igual que Foucault, deberíamos intentar hacer explícitos los ingredientes tecnológicos 
de muchas prácticas sociales y políticas en democracia. Esto supondría volver al ágora con un caleidoscopio más eficaz.

\section{EXPERTOS VERSUS CIUDADANOS: LA TENSIÓN ESENCIAL}

En muchas sociedades contemporáneas el pequeño mercado ha dado paso al mercado de las grandes superficies, se ha cambiado la plaza o mercado popular por localidades-almacén en las que cabe de todo. Este tipo de cambios ha dado lugar a nuevos tipos de relacionales sociales, no solo económicas. Ahora son menos personalizadas y la autoridad del vendedor se reduce a lo que un computador diga al encargado de turno. Quien estás tras un mostrador ya no es una autoridad en lo que vende, sino solo alguien con el poder de pasar el código de barras y cobrarnos.

La autoridad exige aceptación, legitimidad y confianza. Si la pretenden las tecnologías y los ingenieros, tendrán que ganársela junto al respeto, siempre en procesos supervisados. La toma política de decisiones también está supeditada, en democracia, a este tipo de control. En cuestiones de tecnología, esta puede ser el germen de nuevas capacidades y de oportunidades prácticas para la mejora del bienestar humano, pero habrá que vislumbrar de antemano qué se busca hacer con su diseńo, construcción y aplicaciones, pues esas opciones tecnológicas marcarán trayectorias de futuro que tendremos que recorrer. Por ende, convendría reflexionar acerca de ellas y regularlas con buenas políticas científicas.

En una tesitura como la planteada, en la ciudad global del posthumano, del cíborg que somos, se detecta cierta tensión entre los expertos y el orden político que los ciudadanos conformamos de alguna manera. Los expertos buscan influir en las decisiones y los ciudadanos pedimos justicia y más bienestar. Se produce una tensión de corte prometeico (PLATÓN, Protágoras, $322 \mathrm{a}, \mathrm{b})$. En letra del contrato social de Rousseau, nos hacemos ciudadanos cuando somos capaces de distinguir entre lo justo y lo injusto. Y esto nos atańe a todos, no solo a los expertos. Según Protágoras, el conocimiento experto es necesario para ciertos objetivos, no así para la justicia (BRONCANO, 2006, p. 214-216).

Platón toca dos temas que incumben, y mucho, a nuestra época de nuevas tecnologías: por un lado, a la cuestión de la universalidad del conocimiento político justo - nos incumbe a todos $-\mathrm{y}$, por otro, al tema 
de la asimetría entre el juicio experto y el juicio político. ¿Quién manda en la sociedad cíborg? ¿Son los políticos los que ordenan - la política, los ciudadanos, la sociedad - o lo hacen las tecnologías - el conocimiento experto, ciertas oligarquías epistémicas - Se necesita bastante equilibrio aquí y no es fácil obtenerlo. La política muestra muchas facetas, pero los expertos también. Cuando la tecnología se hace política, los ciudadanos comienzan a desconfiar y surge la confusión. Casos como los de las controversias científicas en torno al cambio climático han hecho que las tesis radicales de Collins y Pinch cobren cierta fuerza y credibilidad. ${ }^{16}$ Aunque es cierto que los valores no cognitivos desempeñan un papel importante en la ciencia y la tecnología (PARKER; WINSBERG, 2018), convenimos en que la búsqueda de argumentos epistemológicos nunca está de más en filosofía. Una vía a través de la cual se busca el equilibrio entre saber experto y saber ciudadano o político es la de la reflexión en torno a la gobernanza. ¿Cómo la entendemos? A modo aproximativo, diré que la gobernanza equivale a gobierno adecuado, aquel que busca un futuro ilusionante. Sigo en esto a Bora y Hausendorf (2006, p. 481) cuando señalan que con esta noción estamos refiriéndonos a una nueva forma de trabajo social en común. Esto es, a las actividades horizontales entre instituciones estatales, organizaciones no gubernamentales, empresas privadas $\mathrm{y}$ actores individuales.

La idea de gobernanza nos propone así la sustitución de las antiguas actividades centralizadas por la creación de regulaciones basadas en el trabajo común, la descentralización y la carencia de jerarquías (IRWIN, 1995). Se trataría de conseguir un gobierno justo y eficaz, un gobierno que procurase racionalizar la ciencia y la tecnología con el objetivo de llegar a un equilibrio. Un camino realmente difícil, si bien uno de los más democráticos, pues nos podríamos preguntar acerca del porqué del desarrollo y la inversión en ciencia y tecnología. ¿Es acaso necesaria la investigación, el desarrollo y la innovación $(\mathrm{I}+\mathrm{D}+\mathrm{i}) ?^{17}$ No olvidemos que estas siglas y este proyecto son novedosos, imaginados a partir de la Segunda Guerra Mundial en Estados Unidos y Europa. Fue entonces cuando surgió el proyecto de la Triple Hélice en el que el sistema académico superior de investigación de alto rendimiento, el sistema de financiación de dicho sistema y las tecnologías más innovadoras - y arriesgadas

\footnotetext{
${ }^{16}$ En The Golem (1993), Collins y Pinch subrayaban que en las controversias entre expertos, la ciencia (los expertos) no tiene la última palabra. "En las controversias - afirman -, los científicos muestran sus discrepancias mutuas no solo en lo referido a los resultados, sino también a la calidad del trabajo ajeno" (COLLINS; PINCH, 1993, p. 3). Véase también Frank Fischer (2003).
}

${ }^{17}$ Para una reflexión profunda e interesante acerca de esta cuestión, véase Funtowicz y Ravetz (1993). 
- conformaban cada una de sus aspas. Todo ello estaba acompañado de ciertos sesgos ideológicos y políticos estrechamente vinculados a la economía liberal y que podían poner en jaque la propia noción (ideal) de democracia, no tan sólida y estable como a menudo se ha querido pensar (RAWLS, 1971, p. 329).

La contingencia de la democracia puede ya advertirnos de que un sistema similar al de la Hélice bien puede finalizar más temprano que tarde. Con esto pretendo señalar que todo intento actual por legitimar al posthumano y las nuevas tecnologías tiene que relacionar los procesos de conocimiento con los contextos sociales en que se desarrollan. Las tecnologías parecen estar a la par del conocimiento experto, mientras que la justicia ha de provenir de la democracia. De los varios intentos por vincular las dos partes durante el siglo XX, el mencionado de la gobernanza es el más avanzado. Los otros dos, bien conocidos, fueron el de John Bernal (planificación social de la tecnología) (BERNAL, 1939) y el de Michael Polanyi (proyecto de la República de la ciencia) (POLANYI, 1962; MARSHALL, 2005).

\section{A MODO DE CONCLUSIÓN PROSPECTIVA}

Si no queremos sucumbir al totalitarismo político ni de elites de expertos con intereses no democráticos, nos pedía Theodore Roszak (1968, p.11) que incubásemos en la cultura decadente actual algún virus que diera paso a una contracultura más lúcida. No estamos en la década de 1960, pero en el sistema de bienestar, y más tras la profunda crisis económica iniciada en 2008, ya contamos con relatos que lo ponen en tela de juicio. Entre ellos caben los relatos críticos, por analíticos también, con la ciencia y las tecnologías. Frente a las concepciones justificativas, por interesantes que fueran, de Bernal y de Polanyi, los movimientos críticos con las tecnologías y la imagen posthumana futura comenzaron a cobrar fuerza en la academia y fuera de ella. En el seno de la filosofía, un nombre clave es Paul Feyerabend (1975), quien defendía el anarquismo o pluralismo epistemológico como forma de dar cabida a diferentes sensibilidades acerca del conocimiento. Postulaba dos cosas: que la ciencia es culturalmente variada - esto es, que las diversas ciencias no comparten una misma estructura, tal y como Nagel (1961, p. 324) defendía - y que las reglas metodológicas son del todo evitables. Los posicionamientos más normativistas de otros filósofos - caso claro de Karl Popper - resultaban revertidos con esta propuesta de Feyerabend, quien, junto con otros textos 
seminales de los estudios culturales, consiguió que la filosofía desempeñara su propio papel en la reflexión social, ambientalista y contracultural.

La filosofía académica empezaba a comprender seriamente que el racionalismo de la ciencia y de la tecnología - concebida como ciencia aplicada (BUNGE, 1966) - debía ser complementado, si no mejorado o sustituido, por otras aportaciones conceptuales que incorporaran más elementos vinculados con esas disciplinas. La democratización radical que buscaba Feyerabend mostraría, según mi parecer, que en realidad la impronta de Popper y su sociedad abierta fue más influyente de lo que muchos quisieran aceptar (FULLER, 2005). A diferencia de este, sin embargo, Feyerabend subrayó que lo que en realidad sirve y vale en democracia es la experiencia y la palabra del ciudadano común, su subjetividad, no la de los iniciados y expertos, sean institucionales o formen parte de tanques de pensamiento o gabinetes estratégicos (FEYERABEND, 1975, p. 63). Sigue a Protágoras cuando, provocadoramente, pide que se acepten todas las tradiciones de conocimiento y estilos de razonamiento (FEYERABEND, 1975, p. 63), no solo las científicas. Su noción de democracia radical no acepta la separación nítida entre expertos e ignorantes a la hora de examinar las aplicaciones tecnológicas y los programas de investigación. Su fuerza, como posteriormente han subrayado Fuller o Latour, radica precisamente en su pluralidad, en su apertura a muchos y diversos actores involucrados en la construcción y en la recepción de tecnologías.

Entre todos ellos, cabe destacar el actor posthumano, el ciborg, en torno al cual podemos plantear algunas cuestiones éticas sustantivas e importantes:

[1] La publicidad y la propaganda proyectan a menudo la cara más brillante de la tecnología cíborg, una faz limpia, higiénica, incluso en el plano moral. Considero que debemos ser prudentes al respecto si enfocamos el asunto desde el prisma de una sociedad abierta. La cirugía y la medicina implementadas con prótesis arrastran un alto riesgo de resultados insatisfactorios y de consecuencias colaterales peligrosas. La clave de ello es que el riesgo no es claramente visible, sino mucho más sutil que en el caso de las tecnologías 'más mecánicas'. Son casos más sofisticados, propios a menudo de técnicas parecidas a las de la nanotecnología, en las que el riesgo solo es visible para el experto y no para el paciente-cíborg (en el caso de los injertos, por ejemplo) (SHRADER-FRECHETTE, 1995). 
[2] Es importante también la identidad personal. Si nos injertan algo en el cuerpo, nuestro funcionamiento biológico será (parcialmente) dependiente de la tecnología, la cual puede generar un tipo de conducta controlable por otros y que uno mismo puede que no identifique. En el caso de las prótesis cognitivas (neuroprótesis que ayudan a desarrollar funciones cognitivas), podría darse el caso de que afectasen a la identidad personal. De ahí que, ante las prótesis, sea fundamental proteger el carácter holista del cuerpo humano, la identidad personal íntegra frente a supuestas 'identidades' parciales.

[3] En los procesos de desarrollo cíborg externo, también está en juego la cuestión de la privacidad. Esto es, es posible injertar tecnologías controladas por señales externas al cuerpo modificado. Un chip injertado puede permitir el seguimiento y la monitorización de la trayectoria (física, vital) del sujeto. Los dispositivos sensoriales y las neuroprótesis pueden almacenar información del estado biológico de los sujetos, la cual puede ser objeto de comercialización o mal uso.

[4] Por ende, ¿ante qué somos responsables si estamos sumergidos en un proceso de transformación cíborg? Los injertos tecnológicos en los humanos pueden generar dudas sobre la responsabilidad de estos. El trabajo o funcionamiento de las máquinas (los cíborgs en este caso) determinaría parcialmente el comportamiento y los procesos cognitivos de los portadores humanos. Si un sujeto al que se la ha incorporado cierta tecnología sufriese un accidente o tomase una decisión equivocada, ¿quién o qué sería el responsable? ¿Sería acaso la tecnología un atenuante en un juicio potencial?

El campo de la mejora de los humanos mediante tecnologías es nuevo y vinculado en gran medida a la cirugía estética y a la investigación militar. $\mathrm{Si}$ algunas de esas mejoras son aceptadas socialmente, pueden convertirse en norma hasta el punto de hacer que los sujetos 'no-mejorados' sean tratados como discapacitados. Esto es algo que, de hecho, sucede en torno a los valores estéticos manejados en muchos ámbitos de la industria del entretenimiento y que también tienen un espacio apetecible en el caso de las prótesis cognitivas que puedan mejorar las funciones motoras humanas y las perceptivas. Ante esto, considero que la incorporación de las nuevas tecnologías de la comunicación y de la información con fines de creación cíborg forman la base constituyente de un potencial de acción humana para generar una sociedad más abierta y justa. El avance y el control de estas tecnologías deberían ser dos factores que la filosofía examinase, al menos desde una perspectiva ética, con el fin de, entre otras cosas, actualizar el valor de la propia labor filosófica. En este 
sentido, considero que el desarrollo de acciones éticas aplicadas como son la constitución de códigos éticos, la regulación estatal e internacional, así como la educación en valores (virtudes) morales (al modo en que se ha realizado en las ingenierías) (BENGOETXEA; MITCHAM, 2010), aunque sea algo bastante limitado, es responsabilidad nuestra.

BENGOETXEA, J. B. Technologies for a posthuman open society. Trans/formlação, Marília, v. 44, n. 1, p. 177-200, Jan./Mar., 2021.

\begin{abstract}
The text is divided into two parts. In the first one, I present the development of the cyborg as a cultural and technological entity examined from the perspective of the theory of mind, in which the relevance of various fictional and real elements is underlined. In the second part, I reflect on the future that the cyborg-technological society can bring to human beings. In particular, I aim to show that post-human beings constitute an already established reality that requires a moral and social reflection that focuses on the role of experts in relation to the needs of non-expert citizens. The final conclusion pleads for the constitution of norms and regulations that allow to channel the post-human technological advances in accordance with some ethics applied to humans.
\end{abstract}

Keywords: Cyborg. Posthuman. Experts. Technology. Open society.

\title{
REFERENCIAS
}

ANNAS, G. J.; ANDREWS, L. B.; ISASI, R. M. Protecting the Endangered Human: Toward an International Treaty Prohibiting Cloning and Inheritable Alterations. American Journal of Law and Medicine, Boston, v. 28, n. 2-3, p. 151-178, 2002. BENGOETXEA, J. B. Ética y prostética. In: GALZACORTA, I.; CEBERIO, I.; AGUIRRE, J. (ed.). Diseńando el futuro: Reflexiones desde la filosofía. Madrid: Plaza y Valdés, 2011. p. 183-196.

BENGOETXEA, J. B. Knowledge and Moral Responsibility for Online Technologies. In: GONZÁLEZ, W. J. (ed.). New Perspectives on Technology, Values, and Ethics: Theoretical and Practical. Dordrecht: Springer, 2015. p. 89-103.

BENGOETXEA, J. B.; MITCHAM, C. Ética e ingeniería. Valladolid: Universidad de Valladolid, 2010.

\section{BENNETT, M.; DENNETT, D.; HACKER, P.; SEARLE, J. Neuroscience and} Philosophy: Brain, Mind, and Language. New York: Columbia University Press, 2007. 
BERNAL, J. The Social Function of Science. Cambridge, Mass.: The MIT Press, 1939 [1969].

BORA, A.; HAUSENDORF, H. Participatory Science Governance Revisited: Normative Expectations Versus Empirical Evidence. Science and Public Policy, Oxford, v. 3, n. 7 , p. 478-488, 2006.

BRONCANO, F. Entre ingenieros y ciudadanos: Filosofía de la técnica para días de democracia. Barcelona: Montesinos, 2006.

BUNGE, M. Technology as Applied Science. Technology and Culture, Baltimore, v. 7, p. 329-347, 1966.

CLARK, A. Natural-Born Cyborgs: Minds, Technologies, and the Future of Human Intelligence. Oxford: Oxford University Press, 2003.

CLARK, A. Intrinsic Content, Active Memory and the Extended Mind. Analysis, Oxford, v. 65, n. 1, p. 1-11, 2005.

CLARK, A.; CHALMERS, D. The Extended Mind. Analysis, Oxford, v. 58, p. 10-23, 1998.

CLYNES, M. E.; KLINE, N. S. Cyborgs and Space. In: GRAY, C. H. (ed.). The Cyborg Handbook. New York: Routledge, 1960 [1995]. p. 29-33.

COLLINS, H.; PINCH, T. The Golem: What You Should Know about Science. Cambridge: Cambridge University Press, 1993 [2004].

DE ASÍS, R. Desafíos éticos de los ciborgs. Universitas, Madrid, v. 30, p. 1-25, 2019.

DENNETT, D. The Intentional Stance. Cambridge, Mass.: The MIT Press, 1987.

DENNETT, D. Kinds of Minds: The Origins of Consciousness. London: Phoenix, 1996 [2001].

FERRANDO, F. Philosophical Posthumanism. London: Bloomsbury Academic, 2019.

FEYERABEND, P.K. 'Science': The Myth and Its Role in Society. Inquiry, Oslo, v. 18, n. 2, p. $167-181,1975$.

FISCHER, F. Citizens, Experts, and the Environment: The Politics of Local Knowledge. Durham, NC: Duke University Press, 2003.

FUKUYAMA, F. Our Posthuman Future: Consequences of the Biotechnology Revolution. New York: Picador, 2002.

FULLER, S. Kuhn Vs. Popper: The Struggle for the Soul of Science. New York: Columbia University Press, 2005.

FUNTOWICZ, S.; RAVETZ, J. La ciencia posnormal. Barcelona: Icaria, 1993 [2000]. 
GOMES ROTONDARO, T. Da materialidade às metáforas bem-sucedidas: Reflexôes sobre as transformaçōes materiais e representativas do corpo biológico. Trans/Form/Ação, Marília, v. 41, n. 3, p. 213-228, 2018.

HABERMAS, J. Ciencia y técnica como ideología. Madrid: Tecnos, 1968 [1986].

HACKING, I. The Social Construction of What? Cambridge: Cambridge University Press, 1999.

HARAWAY, D. A Cyborg Manifesto: Science, Technology, and Socialist Feminism in the Late Twentieth Century. In: HARAWAY, D. Simians, Cyborgs, and Women: The Reinvention of Nature. New York: Routledge, 1991. p. 149-181.

HEIDEGGER, M. The Question Concerning Technology and Other Essays. New York: Harper \& Row, 1953 [1977].

HOLBROOK, J. B. (ed.). Ethics, Science, Technology, and Engineering: A Global Resource. Farmington Hills, Mich.: Macmillan Reference USA, 2015.

IRWIN, A. Citizen Science: A Study of People, Expertise and Sustainable Development. London: Routledge, 1995.

JENSEN, C.B. Latour and Pickering: Post-human Perspectives on Science, Becoming, and Normativity. In: IHDE, D.; SELINGER, E. (ed.). Chasing Technoscience: Matrix for Materiality. Bloomington: Indiana University Press, 2005. p. 225-240.

KASS, L. Life, Liberty, and Defense of Dignity: The Challenge for Bioethics. New York: Encounter, 2002.

KURZ-MILCKE, E.; GIGERENZER, G. (ed.). Experts in Science and Society. New York: Kluwer, 2004.

LANDGRAF, E.; TROP, G.; WEATHERBY, L. (ed.). Posthumanism in the Age of Humanism: Mind, Matter, and the Life Sciences after Kant. New York: Bloomsbury, 2019.

MARSHALL, J. Empire, or Cyborg Governance: Divining Systemic Power. In: ANNUAL HAWAII INTERNATIONAL CONFERENCE ON SOCIAL SCIENCES, 4., 2005, Honolulu. Proceedings... [...], Honolulu, 2005, p. 1349-1473.

NAGEL, E. The Structure of Science: Problems in the Logic of Scientific Explanation. New York: Harcourt, Brace \& World, 1961.

NAYAR, P.K. Posthumanism. Cambridge: Polity, 2014.

OLSEN, J. K. B.; PEDERSEN, S. A.; HENDRICKS, V. F. (ed.). A Companion to the Philosophy of Technology. Oxford: Blackwell, 2009.

ORTEGA Y GASSET, J. Meditación de la técnica y otros ensayos sobre ciencia y filosofía. Madrid: Alianza, 1939 [2002]. 
PARKER, W. S.; WINSBERG, E. Values and evidence: how models make a difference. European Journal for the Philosophy of Science, Dordrecht, v. 8, p. 125-142, 2018.

PINEDA, D. La mente humana: Introducción a la filosofía de la psicología. Madrid: Cátedra, 2012.

POLANYI, M. The Republic of Science: Its Political and Economic Theory. Minerva: A Review of Science, Learning and Policy, London, v. 1, p. 54-73, 1962.

RAWLS, J. Teoría de la justicia. Madrid: Fondo de Cultura Económica, 1971 [2002].

ROSZAK, T. El nacimiento de una contracultura: reflexiones sobre la sociedad tecnocrática y su oposición juvenil. Barcelona: Kairós, 1968 [1981].

SAVULESCU, J.; BOSTROM, N. Human Enhancement. Oxford: Oxford University Press, 2009.

SEARLE, J. Minds, Brains, and Programs. In: HAUGELAND, J. (ed.). Mind Designs II: Philosophy, Psychology, Artificial Intelligence. Cambridge, Mass.: The MIT Press, 2000. p. 183-204.

SHRADER-FRECHETTE, K. Technology Assessment, Expert Disagreement, and Democratic Procedures. Research in Philosophy and Technology, Charlottesville, Virg., v. 8, p. 103-105, 1984.

SHRADER-FRECHETTE, K. Evaluating the Expertise of Experts. Risk, v. 6, 1995.

Disponible en: http://www.fplc.edu/RISK/rskarts.htm]. Acceso: 23 febrero 2020.

SLOTERDIJK, P. Normas para el parque humano. Madrid: Siruela, 2000.

TORRES Y QUEVEDO, L. Ensayos sobre automática - Su definición: Extensión teórica de sus aplicaciones. Limbo, Oviedo, v. 17, p. 9-31, 1914 [2003].

TURNER, S.P. Cognitive Science and the Social: A Primer. New York: Routledge, 2018.

WARWICK, K. Cyborg Morals, Cyborg Values, Cyborg Ethics. Ethics and Information Technology, Dordrecht, v. 5, p. 131-137, 2003.

Recebido: 05/3/2020

Aceito: 04/7/2020 
BENGOETXEA, J. B. 